\title{
ÊXODO, DESNATUREZA E OUTRAS PAISAGENS ÉTICAS NA POESIA De Marília Floôr Kosby
}

Martha ALKIMIN*

\section{RESUMo}

A proposta deste artigo se baseia no livro de poemas de Marília Floôr Kosby intitulado Mugido - ou diário de uma doula (2017), cuja paisagem se localiza nas estâncias do extremo sul do Brasil. Ao confrontarem a máquina performativa do patriarcalismo colonial e suas tecnologias de produção de violências, especialmente contra as mulheres e os animais, a poesia de Kosby dá forma a um pensamento-paisagem e a uma poética da relação, para falarmos com Michel Collot (2013), vocalizada a partir de um não lugar ou da não existência histórica e poética atribuída às mulheres. Rejeitando a condição de um não sujeito e de mera nota de rodapé dos discursos universais, a poética que se vê em Mugido opera uma desarticulação da linguagem, a partir da qual se estabelecem relações inéditas de solidariedade entre a poesia e a experiência vivida, ou entre o que há de comum no silêncio das mulheres e no dos animais.

Palavras-chave: Poesia brasileira contemporânea. Marília Floôr Kosby. PensamentoPaisagem. Ètica.

A poeta Marília Floôr Kosby, nascida em Arroio Grande, no extremo sul do Rio Grande do Sul, é também doula de vacas. Sim. Uma doula de vacas, com Doutorado em Antropologia Social pela Universidade Federal do Rio Grande do Sul (UFRGS) e com pesquisa de pós-doutorado na Université de Liège (Ulg), na Bélgica. Além de compor canções, ela ainda atua como colaboradora de alguns grupos de pesquisa nacionais e internacionais como o de Estudos Etnográficos Urbanos da Universidade

Doutora em Letras e Professora do Programa de Pós-Graduação em Letras Vernáculas da Faculdade de Letras da Universidade Federal do Rio de Janeiro/UFRJ, Rio de Janeiro, Rio de Janeiro, Brasil.

E-mail: martha@letras.ufrj.br Orcid iD: https://orcid.org/0000-0003-1455-4146 
Federal de Pelotas (UFPel), Pensamiento crítico caribeo sobre raza y racismo, do Instituto de Filosofia de Havana, e do Méthéor e Cultures Sensibles, na Ulg.

Kosby, que também possui formação em futebol amador, publicou os livros de poesia Os baobás do fim do mundo (2011), Siete colores e um pote cheio de acasos (2013), e o ensaio etnográfico Nós cultuamos todas as doçuras do mundo: as religiões de matriz africana e a tradição doceira de Polotas, pelo qual recebeu dois prêmios: em 2015, o de Boas Práticas de Salvaguardado Patrimônio Imaterial Brasileiro, concedido pelo Instituto do Patrimônio Histórico e Artístico Nacional (IPHAN) e o Açorianos de Literatura em 2016. Em 2017, a poeta publicou o seu terceiro livro de poesia, Mugido - ou diário de uma doula,conquistando o selo de finalista do Prêmio Jabuti na categoria poesia em 2018. No recente livro As 29 poetas hoje (2021), organizado por Heloísa Buarque de Hollanda, o nome de Marília Kosby figura ao lado de Adelaide Ivânova, Danielle Magalhães, Regina Azevedo, Bruna Mitrano, por exemplo, autoras de uma poesia de forte compromisso com a reflexão ético-polítco sobre o presente que merece uma leitura demorada pelo valor do que anunciam em suas poéticas ou, diria mesmo, em suas políticas de escrita.

E é exatamente sobre Mugido - ou diário de uma doula de que falará este artigo, pelas seguintes motivações: por se tratar de um livro que participa do cenário da poesia contemporânea brasileira tematizando uma paisagem não urbana lida por uma mulher; por colocar em tensão as representações da vida do interior, em particular a das mulheres e dos animais; e porquea operação poética de Kosby desdobra-se numa espécie de pensamento-paisagem, assim como numa poética da relação, para falar com Collot (2013), por meio de um processo de desarticulação radical do logos normativo do patriarcado colonial, especialmente no que se refere às suas tecnologias de produção sistemática de violência.

Em outras palavras, ao confrontarem a máquina performativa do patriarcalismo em suas dimensões ético-políticas, e por que não dizer também epistemológicas, ao criarem fissuras e falhas no corpo dessa linguagem feita de universais, os poemas de Kosby dão forma a uma espécie de anti-linguagem que se constrói pela voz de um animal, ou seja, 
da mulher. É desse lugar de não sujeito da história - mas sobre quem recai o peso de todas as ficções jurídicas, políticas, psicanalíticas e científicas que Mugido - ou diário de uma doula tensiona tanto a imagem do macho adulto branco sempre no comando (VELLOSO, 1983) quanto a longa tradição metafísica que supõe uma diferença inerente entre humanos e não humanos. Sem linguagem, sem logos, mulheres e animais compartilhando a solidariedade muda entre viventes, e a fatura poética que Marília Floôr Kosby alcança ao percorrer as paisagens dessa aliança é o que nos interessa discutir.

Kosby, que da infância à vida adulta acompanhou o seu pai em inúmeros atendimentos veterinários pelas regiões campeiras do sul, em cada poema de Mugido reelabora afetiva e politicamente as paisagens de sua Arroio Grande escrevendo ora as imagens de ovelhas, galinhas e terneiros, ora dos matadouros, até nos colocar diante do "tremor derradeiro de uma vaca antes de cair de joelhos sobre o próprio sangue" (KOSBY, 2017, p. 18). Em cada paisagem, uma experiência vivida e um pensamento. Em cada poema, um estado de reflexão a se desdobrar numa poética da relação (COLLOT, 2013) e na aliança solidária entre as mulheres e todos os viventes não humanos, conforme se verá nos poemas escolhidos adiante.

Antes disso, porém, é necessário um recuo teórico no que diz respeito às noções de paisagem, pensamento-paisagem e poética da relação em que este artigo se apoia. Como se sabe, a paisagem sempre foi objeto de estudo das ciências sociais mais diversas, além da História e da Geografia. Da Arqueologia à Etnologia, passando pela Antropologia, Psicologia, Economia ou Sociologia, os estudos sobre a paisagem reiteram a complexidade dos fenômenos humanos e sociais, tensionando tanto as nossas coordenadas epistemológicas centrais como as relações tempoespaço, sujeito-objeto e as consequentes cisões, seja entre natureza e cultura, o inteligível e o sensível ou entre o real e o imaginário, por exemplo.

$\mathrm{O}$ fato é que a paisagem se oferece ao pensamento ou faz pensar. Nos termos de Collot (2013, p. 12), "a paisagem propõe-nos entre outras coisas, um modelo para a invenção de um outro tipo de racionalidade, 
que denomino pensamento-paisagem". Ao evocar o termo, o teórico frisa que a um só tempo a paisagem tanto provoca o pensar quanto o próprio pensamento se desdobra em paisagem, num continuum que se retroalimenta.

Nessa perspectiva, a paisagem nem é representação, nem uma simples presença, mas sim o resultado do encontro entre o mundo e um ponto de vista; uma interação que nos leva a pensar de outro modo. E a poesia é um lugar privilegiado para refletir se sobre essa interação, sobretudo porque o pensamento-paisagem "implica um sujeito que não reside mais em si”, mas que por força do encontro e da interação de seu ponto de vista e o mundo, ele "se abre ao fora"; uma experiência, portanto, que redefine a própria "subjetividade humana não mais como uma substância autônoma, mas como relação”. (COLLOT, 2013, p.30).

São essas balizas teóricas que me interessam movimentar ao percorrer as leituras de certos poemas de Mugido - ou diário de uma doula. Interessa-me a voz que sai de si para cumprir o "êxodo/de uma tal condição humana" e assim encontrar-se livre para sustentar-se em total estado de pensamento-paisagem para migrar rumo a uma poética da relação. Nos poemas de Mugido, esse processo de elaboração de um pensamento-paisagem ressoa ainda mais no contexto do nosso adoecimento coletivo com a pandemia da COVID-19. O vírus, esse outrouniversal e negativo de nós mesmos, pôs em xeque a viabilidade da presença humana no mundo decorrente de nossa mutação de espécie em força geológica destrutiva: nós e nossos combustíveis fósseis, nossas formas de liquidação da vida, nossa industrialização da experiência, nossa compulsão pela diversão a qualquer preço; nós e essa sanha pelo extermínio; nós e toda essa desnatureza diante da qual tem sido inútil dizer mind the gap.

Esse ressoar de um pensamento-paisagem nos poemas de Kosby interessa-me também pela enunciação ético-política endereçada às ruínas do presente. Uma voz fora de si, repito, que se evade de uma tal condição humana, e, como um fio de corte, dá início à procura de uma poética da relação, como se lê no poema de abertura de Mugido: 
$\mathrm{mmmmmm}$

mais ou menos que um livro,isto é um êxodo

de uma tal condição humana

o mugido foi a ação escolhida para essa desarticulaçãoparem de ver uma vaca mugir

já nem digo ouvir

ouvir é difícil, o mugido de uma vaca parem de ver e procurem a próxima notaem que a palavra daria

aquela melodia aquele esforço todo

de guela, olho, bucho, língua, rúmen

que fecunda epifania valeriaaquele esforço todo?

traduzam

o mugido

Há no poema uma constelação de acontecimentos. A começar pelo título, $m m m m m m$ - essa materialidade do mugido de uma vaca, que já é em si a evocação de um pensamento-paisagem a nos enviar para um fora da linguagem humana com "aquele esforço todo / de guela, olho, bucho, língua, rúmen.” Pelo mugido, o poema anuncia que olivro - designado como isto, um pronome demonstrativo inespecífico - é "um êxodo/de uma tal condição humana", como se agora a poesia se fizesse apenas pela linguagem animal; como se ela exigisse uma transmutação tal da linguagem, que somente pela opçãode se evadir dela, de abandoná-la, fosse possível lhe devolver a potência domugido de uma vaca e a sua melodia fecunda. No poema, "o êxodo/de uma tal condição humana" é também uma procura e um desejo relacional com outros viventes; umadesarticulação para articular uma ideia de natureza que nos relembre nossa própria animalidade.

mmmmmm também pode ser pensado como a ruptura radical, como um salto em direção ao próprio animal que somos e talvez esse gesto possa conter, tomando por empréstimo as palavras Nascimento (2020, p. 13), "a possibilidade de dar a volta por cima no que se refere à tragédia colonizadora do homem”, a todas as referênciasredundantes de 
nós mesmos e a toda a desnatureza que nos cerca. O mugido, comoum devir paisagem, por sua vez, traz consigo a ideia da própria animalidade da escrita poética, esse corpo animal com sua estranheza desafiadora, com sua destinação à alteridade, ao outro de nós, cuja complexidade desafia a compreensão por se inscrever fora do cogito cartesiano, mas, dirá Collot (2013, p. 31), no "cogito perceptivo", que "supõe a abertura da consciência ao fora”, e onde a percepção, os sentidos já são em si uma atividade ou uma forma específica de produção pensamento.

Mais do que um ponto de vista subjetivo, a paisagem como conceito também é tributária do movimento, do deslocamento, do deslizamento dos corpos e objetos. E nesse sentido, o título do poema - $\mathrm{mmmmmm}$ - transporta uma noção de paisagem que não se restringe à percepção de um sujeito que com ela interage, mas a amplia, se pensarmos que $a$ paisagem, na perspectiva formulada por Gerard (2006, p. 57), "é alguém que intervém na paisagem”. O mugido de uma vaca é um deslocamento sonoro na paisagem que cria nela uma intervenção paradoxal. Ouve-se o mugido, sua presença está ali na paisagem; entretanto, aquilo que dele se apreende é sua intraduzibilidade, a não ser que o sujeito da escuta se desloque, como e com o mugido, para um devir animal. Somente por meio desse deslocamento se pode entender a pergunta: que fecunda a epifania valeria/todo aquele esforço?

Os versos finais do poema - "traduzam/o mugido" - num enjambement - essa cavalgada animal da escrita - descrevem o andamento circular do poema, pois que para traduzir o mugido, essa intervenção melódica na paisagem, somente pelo êxodo/de uma tal condição humana é nos facultado o encontro com essa epifania e com a proposição de uma poética da relação criada por Marília Kosby. Então, se todo êxodo supõe uma desarticulação dos regimes de sentido e dos sistemas de referências consensualizados e compartilhados social e historicamente; se o primeiro poema de Mugido - ou diário de uma doula aticamo procedimento poético uma linguagem, e diria, uma escuta animal, no poema a seguir, que dialoga com o um útero é do tamanho de um punho, de Freitas (2017), lê-se a paisagem a partir de um cogito corporal (COLLOT, 2013, p. 41), ou de 
uma experiência encarnada que em certa medida une as mulheres e aos animais.

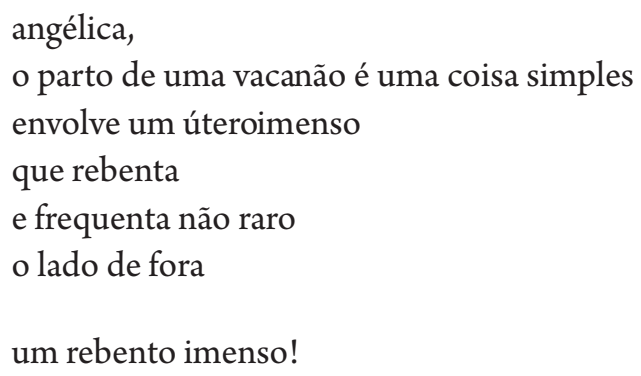

um rebento imenso!

o parto de uma vacarequer punhos firmes finos porém

matar uma vacanão é uma coisa simplesrequer um tiro certeiro alto calibre o ponto preciso longedo meio da testa dois cavalos três ou quatro homensum guri quem sabe uma mulhercarnear uma vaca exige sangrá-la até a última gotapara que a carnenão termine preta sangrar uma vacaé para exímios comer uma vaca porém

No poema, há três imagens em movimento: o parto de uma vaca, "que requer punhos finos e firmes", a morte de uma vaca a tiros, e o carnear do animal e seu sangramento "até a última gota". Como se sabe, no poema de Freitas, o útero da mulher é o eixo da problematização sobre seu sequestro e apropriação de seu corpo pelo patriarcado e nele cabem "capelas/bancos hóstias crucifixos/cabem senhoras católicas/que não usam contraconceptivos" e todas formações discursivas da ciência, das religiões ou da mídia que revelam a ordem de expropriação da mulher em 
relação ao seu próprio corpo e desejo. Quem "pode dizer que tenho um útero/(o médico) quem pode dizer que funciona (o médico)/ i midici”, escreve Angélica Freitas.

Em certa medida, o poema de Freitas (2017) funciona historicamente como um habeas corpus - do latim: que tenhas o (teu) corpo (em liberdade) - e, nesse sentido, ao recuperá-lo e colocá-lo na paisagem campeira, Kosby tanto reitera a politização do útero quanto desloca esse questionamento para o mundo dos abatedouros de animais trazendo de lá a mesma animalidade, a mesma prática de extermínio: "matar uma vaca/ não é/ uma coisa simples/ requer um tiro/ certeiro/ de alto calibre”. Se continuarmos a leitura lado a lado dos poemas de Freitas e Kosby, um núcleo comum também está presente na postura antiespecismo e na reflexão ético-política que tensiona a discriminação e o suposto direito da espécie humana de explorar, escravizar e matar as demais espécies de animais por considerá-las inferiores. Em outros termos, as vacas e as mulheres, como animais de uma espécie inferior aos olhos do patriarcado, são mercadorias de que se pode dispor, apropriar-se e matar.

Assim aconteceu com Mariele Franco, naquele 14 de março de 2020. Quatro tiros certeiros em sua cabeça; assim prosseguem os feminicídios, os estupros, a morte de inúmeras mulheres obrigadas a realizar um aborto ilegal. Todas essas vacas, poderia dizer um miliciano carioca, mereceram morrer e sangrá-las é para exímios. O especismo como um imaginário soberano e narcisicamente autorreferente, se dirige não apenas aos animais, mas alcança igualmente as questões de gênero e raça e tudo o que vive.

O poema de Kosby ainda nos endereça para outra paisagem de ausências, a das mulheres do campo que, como as vacas, são uma nãovida,uma presença ausente que compartilha uma solidariedade muda em relação aos animais de criação. Como lembra Kosby (2017, p. 115), na entrevista do posfácio de seu livro, elasos veem "morrer, copular, parir, tem uma experiência transespecífica com os corpos de outras mamíferas, que é visceral". São "fêmeas todas, a mulher reconhece seu útero, suas tetas, sua vagina, sua libido, seu fenecer pelas vacas, porcas, cabras” (p. 113).Isto é o 
que se percebe também no pequeno poema em prosa que descreve outra paisagemíntima entre as mulheres e os animais:

"Quando fui ganhar o Jefferson, eu não tive dilatação. Foi uma luta pra ele nascer. Eu quase morri”. Deitada sobre a vaca, Jaqueline desconfia até do veterinário. O pai me conta depois que isso é comum de acontecer: "A Deise, lá da figueirinha, se torcia toda, quando eu fazia a injeção nos bichos parecia que era nela que eu estava fazendo". (KOSBY, 2017, p. 81).

Ou como na seguinte estrofe de outro poema, também sem título, na qual os versos dizem:

minha mãe não me viu nascer

parecia que tinham carneado uma vacao

frio dos ferros entre as coxas

a sangueira pelo chão

(KOSBY, 2017, p. 73).

Um útero e uma não língua, um corpo em ausência: eis mais um pensamento-paisagem que se erige em segredo sobre a vida das mulheres do campo e sua comunicação simbiótica e harmoniosa com os animais. Com seus corpos, entre ferros, ou sendo alvo de tiro ou de faca, as mulheres, ao assistirem nas charqueadas ao carnear de uma vaca, sua igual até à sua sangria final e compartilham uma disponibilidade sensível para a alteridade; para encontrar-se no fora da experiência da brutalidade dos homens, como se professassem silenciosamente "o humanismo do outro" (NASCIMENTO, 2020, p. 13), a mais urgente das desarticulações e o nosso êxodo mais decisivo, porque, como aponta Berardi (2020), esse sujeito da história, esse homem e sua lógica sexista, racista, descriminatória e perversa, está em vias de perder a sua centralidade, o seu posto de motor universal do processo histórico.

Por isso, uma mulher que escreve de dentro dos pampas, com sua cabeça de vaca louca, com seus olhos dentro da carne, com sua vivência de doula e que sabe como se faz um rebanho; uma mulher com seus versos 
que evocam tímpanos e espinhaços de ovelha; uma poeta que luta contra a morte e dela faz nascer uma poética da relação entre, com e pelos os viventes, fissurando dessa maneira a tradição de uma metafísica que opõem humanos e não humanos, como se diz por aí "nãoquer briga com ninguém, bicho", porque ela está "virando outra coisa/ e vou virando outra coisa dentro do espaço/ viro outra coisa/ viro outra coisa/ vou virando/ utra coisa/viro a pata/do burro/no voo do coice/dói-me o esporro dado/ mais do que a cara/a tapa”.

EXODUS, DESNATURE AND OTHER ETHICAL LANDSCAPE IN THE POETRY OF Marília Floôr Kosby

\section{Abstract}

The purpose of this article is based on the book of poems by Marília Floôr Kosby entitled Mugido - ou diário de uma doula (2017), whose landscape is located in the far south of Brazil. When confronting the performative machine of colonial patriarchalism and its technologies for producing violence, especially against women and animals, Kosby's poetry gives shape to a landscape-thought and a poetics of the relationship, to speak with Michel Collot (2013), vocalized from a non-place, or from the historical and poetic non-existence attributed to women. Rejecting the condition of a non-subject and a mere footnote to universal discourses, the poetics seen in Mugido operates a disarticulation of language, from which unprecedented relations of solidarity are established between poetry and lived experience, or between what is common in the silence of women and animals.

KeYwords: Contemporany poetry. Marília Floôr Kosby. Landscape-thought. Ethic.

ÉXODO, DESNATURALIZACIÓN Y OTROS PAYSAJES ÉTICOS EN LA POESÍA DE Marília Floor Kosby

RESUMEN

El propósito de este de este artículo se basa en el libro de poemas de Marília Floôr Kosby titulado Mugido - o diario de una doula (2017), cuyo paisaje se ubica en 
el extremo sur de Brasil. Al confrontar la máquina performativa del patriarcado colonial y sus tecnologías para producir violencia, especialmente contra mujeres y animales, la poesía de Kosby da forma a un pensamiento-paisaje y una poética de la relación, para hablar con Michel Collot (2013), vocalizado desde un no -lugar, o de la inexistencia histórica y poética atribuida a la mujer. Rechazando la condición de no sujeto y mera nota al pie de los discursos universales, la poética vista en Mugido opera una desarticulación del lenguaje, a partir de la cual se establecen relaciones de solidaridad inéditas entre la poesía y la experiencia vivida, o entre lo común en el silencio de mujeres y animales.

Palabras clave: Poesía brasileña contemporánea. Marília Floôr Kosby. Pensamientopaisaje. Ética.

\section{REFERÊNCIAS}

BERARDI, Franco. Além do colapso: três meditações sobre um possível depois. 2020. Disponível em: https://leicufrj.wordpress.com/2020/04/02/alem-docolapso-tres-meditacoes-sobre-um-possivel-desenlace-por-franco-bifo-berardi/ Acesso em: 23 fev. 2020.

COLLOT, Michel. Poética e filosofia da paisagem. Rio de Janeiro: Oficina Raquel, 2013.

GERARD, Jean Louis. Paysage et esthétique: de la representation à la mise èn scène. In: GUNCH, Daniel Vander; VARONE, Frédéric (org.). Le paysage à la croisee des regards. Bruxelles: La Letter Volée, 2006.

HOLLANDA, Heloísa Buarque (org). As 29 poetas hoje. São Paulo: Companhia das Letras, 2021.

KOSBY, Marília Floôr Kosby. Mugido - ou diário de uma doula. Rio de Janeiro: EdiçõesGarupa, 2017.

KOSBY, Marília Floôr Kosby. Nós cultuamos todas as doçuras do mundo: as religiões de matriz africana e atradição doceira de Polotas. Porto Alegre: Editora Escola de Poesia, 2015.

KOSBY, Marília Floôr Kosby. Siete colores e um pote cheio de acasos. Rio de Janeiro: Editora do Autor 2013. 
KOSBY, Marília Floôr Kosby. Os baobás do fim do mundo. Porto Alegre: Editora Escola de Poesia, 2011.

NASCIMENTO, Evando. Notas sobre o coronavírus e a sobrevivência das espécies.2020. Disponível em: https://www.n-1edicoes.org/textos/66. Acesso em: 8 mar. 2020.

VELLOSO, Caetano. O estrangeiro. Nova York,1989. Disponível em: https:// www.youtube.com/watch?v=faPc0Uxa3F4. Acesso em: 24 abr.2020

Submetido em 31 de janeiro de 2021

Aceito em 19 de abril de 2021

Publicado em 30 de maio de 2021 